\title{
Wenn die Notenlinien zum Drahtverhau werden. Aggressivität und Musik in Ingmar Bergmans Drehbuch Herbstsonate und in Elfriede Jelineks Roman Die Klavierspielerin
}

\begin{abstract}
Scenariusz filmu Jesienna sonata Ingmara Bergmana i powieść Pianistka Elfriede Jelinek dotyczą skomplikowanej relacji miedzy matką a córką. Wydając córkę na świat, matka daje jej życie, ale z chwilą tą rozpoczyna niszczyć jej osobowość. Wydaje się, że w składającym się z elementów męskich i żeńskich świecie nie ma już miejsca dla córek, które przez matki traktowane są albo jako części ich samych, albo jako trzecia płeć. W obu tekstach agresja wyzwalana przez matki związana jest $\mathrm{z}$ muzyką, która ujawnia, że ich samorealizacja odbywa się na koszt córek.
\end{abstract}

Das Drehbuch des Films Herbstsonate von Ingmar Bergman und der Roman Die Klavierspielerin von Elfriede Jelinek betreffen die komplizierte Beziehung zwischen Mutter und Tochter. Die Mutter gibt der Tochter das Leben, indem sie sie zur Welt bringt, aber von diesem Moment an beginnt sie auch ihre Persönlichkeit zu vernichten. Es scheint, dass es in einer aus männlichen und weiblichen Elementen bestehenden Welt keinen Platz mehr für die Töchter gibt, die von den Müttern entweder als Teil von sich selbst oder als ein drittes Geschlecht behandelt werden. In beiden Texten hängt die von den Müttern ausgelöste Aggression mit der Musik zusammen, die offenbart, dass ihre Selbstverwirklichung auf Kosten der Töchter stattfindet.

The screenplay of the film Autumn Sonata by Ingmar Bergman and the novel The Piano Player by Elfriede Jelinek deal with the complicated relationship between a mother and a daughter. The mother gives life to the daughter by bearing her but from this moment on she begins to destroy her personality. It seems that in a world composed of male and female elements there is no more place for the daughters that are treated by the mothers either like parts of themselves or like a third sex. In both texts 
the aggression caused by the mothers is connected with the music which reveals that their self-realization takes place at the daughters' expense.

Eva, die Protagonistin des Filmdrehbuches Höstsonaten [Herbstsonate] (1978) von INGMAR BERGMAN (1918-2007), formuliert den folgenden Gedanken in Bezug auf die Mutter-Tochter-Relation:

En mor och en dotter, vilken fruktansvärd kombination av känslor och förvirring och förstörelse. Allt är möjligt och allt sker i kärlekens och omsorgens namn. Moderns skador ska ärvas av dottern, moderns missräkningar ska dottern umgälla, moderns olycka ska bli dotterns olycka, det är som om navelsträngen aldrig blivit avskuren. Dotterns olycka är moderns triumf, dotterns sorg är moderns hemliga njutning. (BERGMAN 1978:73)

Mutter und Tochter, was für ein schreckliches Konglomerat aus Gefühl, Verwirrung und Zerstörung! Alles ist erlaubt, und alles geschieht im Namen der Liebe und Güte. Die Schäden der Mutter erbt die Tochter, für die Enttäuschungen der Mutter kommt die Tochter auf, das Unglück der Mutter muß das Unglück der Tochter werden - es ist, als sei die Nabelschnur niemals durchtrennt worden. Das Unglück der Tochter ist der Triumph der Mutter, die Trauer der Tochter ist die heimliche Freude der Mutter. (BERGMAN 1980:62f.)

Diese Beobachtung bewahrheitet sich auch im Falle des Romans Die Klavierspielerin (1983) von ELFRIEDE JELINEK (geb. 1946), den der in beiden Werken auftretende und sich um das Klavierspielen realisierende Kontext der Musik an das Drehbuch von Bergman heranrückt: Auf dem Gebiet der Musik sind sowohl die weltberühmte Pianistin Charlotte und ihre laienhaft Klavier spielende Tochter Eva bei Bergman als auch die Klavierlehrerin Erika und ihre von der Klavierkarriere träumende Mutter bei Jelinek situiert. Die Konstellationen dieser Double-Bind-Beziehungen sind auf separate Handlungsflächen zurückzuführen, die sich aber überschneiden. Charlotte, die ihrer Tochter den Zugang zu sich verwehrt und sie auf der gegenüberliegenden Seite der von den Notenbögen gebildeten Mauer isoliert hält, verlässt das Terrain der Kunst infolge einer vorübergehenden Indisposition und wechselt in das nicht mehr künstlerisch, sondern gesellschaftlich bestimmte Territorium der Tochter über, um nach einiger Zeit auf den früher eingenommenen Platz zurückzukehren. Die Periode ihres Zusammenseins weist die gleichen Züge auf, die das Zusammenleben von Erika und ihrer Mutter kennzeichnen, auch wenn Erikas Mutter gerade die Position anstrebt, die Charlotte als anerkannte Pianistin behauptet und die hinter der durch die Notenblätter geformten Grenze zu erreichen ist, wo das Gesellschaftliche endet und das Künstlerische beginnt. Sowohl bei Bergman als auch bei Jelinek werden also die Notenlinien zu Stacheldrähten, obwohl sich die Mütter und die Töchter auf unterschiedlichen Seiten der so gebildeten Verhaulinie befinden: Evas 
Mutter trennte sich durch diese Linie von der Tochter und von der ganzen Außenwelt, um in der Innenwelt mittels der Musik existieren zu können; dagegen ist Erikas Mutter bestrebt, mittels der mit sich geschleppten Tochter in das sich hinter dieser Linie erstreckende Gebiet der Musik vorzudringen, um sich von dem ,trivialen" Teil der Außenwelt zu trennen und in deren ,edlerem', lukrativem Teil Fuß zu fassen. Nicht nur den Bemühungen von Erikas Mutter, die auf die unabdingbare Fesselung ihrer Tochter abzielen, sondern auch den Eva aus- und einsperrenden Bewegungen von Charlotte wohnen Elemente der Aggressivität inne, deren Zusammenhang mit der Musik das Untersuchungsziel des vorliegenden Textes ausmacht. Mit der angeführten Stelle aus Bergmans Werk, die das Mutter-Tochter-Verhältnis betrifft, sind so die Konturen der Mutter-Tochter-Bindung angedeutet, in der die Vielfalt und die Vieldimensionalität der Existenzaspekte fokussiert werden. Die Tochter kann als Fortsetzerin der Existenz der Mutter gelten, wodurch sie im Voraus in ihrer Autonomie beeinträchtigt wird, was sie zu der anderen Hälfte des ,mütterlichen“ Daseins abstempelt. Diesem in Jelineks Werk dargestellten Typ der Tochter wird die in Bergmans Drehbuch präsentierte Tochter gegenübergestellt, die als eine Widersacherin angesehen werden kann, der man das Weibliche abspricht und - wegen der Unmöglichkeit der Verwandlung in einen Mann - den Status des ,dritten“ Geschlechts im Hinblick darauf gewährt, dass eine Frau in einer anderen Frau weder das Eigene noch das Gegensätzliche findet. Lebt Eva in einem Identitätsvakuum, weil sie sich in der männlich-weiblich bestimmten Wirklichkeit nicht zu verankern vermag, so kommt Erika ein Leben in einem Identitätsgedränge zu, weil sie in dieser Wirklichkeit keinen eigenen Platz hat und ihn mit der Mutter teilen muss. Obwohl aus den der Analyse unterzogenen Werken Filme entstanden sind - bei Bergman als direkte und bei Jelinek als indirekte, adaptierte Übertragung des Textes -, wird den Verfilmungen hier kaum Rechnung getragen, weil gegenüber der Abgeschlossenheit der Bilderausgabe im Film der in Nuancen bestehenden Unendlichkeit der Bildergenerierung durch den Text der Vorrang gegeben wird. Wegen des großen literarischen Gehalts von Bergmans Drehbüchern (ANTONIEWICZ-DURCZAK 1992) bildet eher die Wort-Dimension der Texte als die Bild-Dimension der Filme eine dem Werk von Jelinek und dem Werk von Bergman gemeinsame Ebene.

Eva und ihre Mutter gehören zwei unterschiedlichen Existenzbereichen an, die von der Liebe zum Menschen im Fall der Tochter und von der Liebe zur Kunst in Charlottes Fall abgesteckt werden. Dass Charlotte dank der Musik auflebt, wird gleich am Anfang des Werks offenkundig: Als sie in das Haus der Tochter kommt, wird ihre leichenartig anmutende Spannung sofort abge- 
baut, sobald sie ein Paar Klaviertasten drückt und einige Klänge hört (BERGMAN 1978:33; BERGMAN 1980:28). Nicht ohne Bedeutung war die Musik auch in ihrem Zusammenleben mit Leonardo, Charlottes verstorbenem Partner, der Cellokonzerte gab und mit ihr oft privat musizierte, was ein festes Fundament ihrer Beziehung bildete und als eine Plattform funktionierte, auf der die Gefühle der beiden zirkulieren konnten. Es ist evident, dass Charlotte außerstande ist, Gefühle in der Wirklichkeit zu zeigen. Ihre Domäne der Emotionen ist eben die Musik, was deutlich zum Ausdruck kommt, wenn sie ihr schlechtes Befinden in den Bereich der Musik transportiert, wo das Negative der erlebten Wirklichkeit verarbeitet und in das Positive der Kunst konvertiert wird. Charlottes Besuch bei der Tochter zielt nicht darauf ab, die Kluft der Missverständnisse zwischen ihr und Eva zuzuschütten, sondern wird der Musik untergeordnet: Hier fällt ihr endlich die richtige Interpretationsweise einer Sonate von Bartók ein, womit sie sich für die Unbequemlichkeiten des Aufenthalts im Pfarrhaus entschädigt (BERGMAN 1978:25f.; BERGMAN 1980:21f.). Wie geschickt sich Charlotte auf dem Gebiet der Musik bewegt und wie heimisch sie sich dort fühlt, zeigt die Szene, in der sie und Eva dasselbe Prélude von Frédéric Chopin vorführen. Die Ausführung von Eva, deren Interpretation unbeholfen und tollpatschig wirkt, hebt sich von der Ausführung der Mutter ab, deren Spielweise von Eleganz und Anmut geprägt ist. Der Wettbewerb, in dem die Stärke des Spiels von Eva in den von ihr freigelassenen und in das Prélude ,hineingewobenen' Gefühlen besteht, fällt im Endresultat doch zugunsten von Charlotte aus, deren Spiel es erlaubt, die Gefühle durch die Musik an die anderen weiterzuleiten, d.h. die Gefühle der Zuhörer wachzurufen und nicht bloß die enthüllten Gefühle des Musikers zu empfangen.

Die Andersartigkeit der Realität und der Kunst wird mit Hilfe der Metapher des Wassers signalisiert, auf die man bei Bergman relativ oft stößt. Als Eva sich an das Bild der Mutter erinnert, mit der sie als Kind im Boot auf der See gefahren war, zeichnet sich in ihrem Gedächtnis eine Silhouette ab, die von der Beschreibung und Situation her mit der Gestalt einer Seejungfer zu verwechseln ist (BERGMAN 1978:58; BERGMAN 1980:48). Den Vergleich mit der Seejungfer vervollständigt die Stelle, in der von der schönen Stimme der Mutter die Rede ist (BERGMAN 1978:61; BERGMAN 1980:51). Ließen die Seejungfern die von ihren schönen Körpern und hinreißenden Gesängen verzauberten Seeleute das Rudern vergessen und an den Klippen zerschellen (PARANDOWSKI 1992:25), so hat die Stimme der Mutter bei Eva eine umgekehrte, nämlich eine rettende Funktion. Indem sie nicht dem, was die Mutter sagte, sondern dem Träger des Gesagten Aufmerksamkeit schenkte - also der 
Stimme, die wie das Kind während der Geburt aus dem Inneren der Mutter kommt -, konnte sie die richtigen Intentionen von Charlotte erkennen, die diese zwar mit ihren Worten zu vertuschen versuchte, aber gleich mit ihrem Handeln bloßlegte. Das dem Wort ,Seejungfer“ entnommene Lexem ,Jungfer', mit dem Charlotte assoziiert wird, betont den Mangel an Sorge für das Kind - die Sorglosigkeit, die bei den (See-)Jungfern aus Mangel an Kindern resultiert und die sich bei Charlotte aus dem Aussetzen des Kindes und aus den oppositionell konzipierten, auf die unterschiedlichen Elemente Wasser (Charlotte) und Luft (Eva) zurückgehenden Handlungsbereichen der beiden ergibt. Davon, dass Charlotte der Wasser-Sphäre und nicht wie Eva der LuftSphäre zuzuordnen ist, zeugt auch ihr Verhältnis zu den Tränen als Form des Wassers. In der Szene, in der Eva Charlotte nach sieben Jahren wiedersieht, weint nur die Tochter vor Freude über das Zusammentreffen mit der Mutter: Aus der Sicht der gläubigen Eva können die sieben Jahre die sieben Tage von Gottes Welterschaffung reflektieren und an die Mutter-Tochter-Beziehung als an einen gleich nach dem siebten Tag abzuglättenden Riss in seiner perfekten Weltkonstruktion denken lassen. Auf dem Gesicht der Mutter dagegen erscheint keine Träne. Erst während der Dusche ist ihr zum Weinen zumute, aber sie weint auch dann nicht, und diese Tätigkeit - nicht in stofflicher, sondern in förmlicher Hinsicht - drückt eher das aus der Dusche spritzende Wasser aus. Im Weinen der Tochter ist die Sehnsucht nach der Rückkehr ins Fruchtwasser der Mutter zu erblicken, die eine Integration sowohl mit der Mutter als auch mit einem anderen Menschen chiffriert. Deshalb ertrug Charlotte die Tränen der anderen - auch die der Tochter - nicht, was Eva in den gegen die Mutter gerichteten Vorwürfen besonders stark akzentuiert: Die Tränen konnte die Mutter mit dem ,Zurückströmen“ eines Menschen - sei es eines Kindes oder einer fremden Person - in den Schoß der Frau und so mit dem Eintritt in ihre Existenzsphäre gleichsetzen, wodurch eine physische Nähe initiiert wird, die dann in eine Nähe auf der psychischen Ebene zu überführen ist. Da Charlotte die Tochter „Heulsuse“ (BERGMAN 1978:26; BERGMAN 1980:22) nennt, ist anzunehmen, dass Eva ihren Hunger nach mütterlicher Nähe häufig manifestieren musste. Für Charlotte dagegen haben die Tränen keine Bedeutung, weil es einerseits keine weibliche Person in ihrer Umgebung gibt - außer ihren Töchtern, in die sie als ihre Mutter nicht ,zurückströmen ' und in deren Schöße sie nicht zurückkehren kann - und weil sie andererseits durch das Wasser sowohl von außen (die sie zur [See-]Jungfer machende Wasserumgebung) als auch von innen (die aus ihr eine Mutter machende [Frucht-]Wassererfüllung) gekennzeichnet ist. Vor diesem Hintergrund kann das Wasser aus der von Charlotte genommenen Dusche an die 
Tränen erinnern, die sie in sich saugt, um zu ihrem natürlichen, den Musikbereich inkarnierenden Milieu zurückzukehren - dem Wasserambiente, das ihren Mangel an Tränen beim Wiedersehen der Tochter damit entschuldigen lässt, dass sie so unsichtbar waren, wie die Tränen einer ins Wasser getauchten Person unbemerkbar bleiben. Da Charlotte nach dem Duschen eine Stunde Schlaf plant, ist darauf zu schließen, dass nur der Schlaf die Möglichkeit bietet, aus dem Bereich der Musik herauszutreten, in dem es bei jedem Schaffensakt zu einer starken Exploitation des künstlerischen Ichs kommt, ohne zu oft in die Wirklichkeit einzutreten. Auch wenn sich die Wirklichkeit in den Schlaf in Form der Träume einschleicht, so wird sie doch bloß in filtrierter Gestalt widergespiegelt, aber nicht eingelassen. Es ist bezeichnend, dass Charlotte auch den Tod des Mannes, mit dem sie verbunden war, nicht beweint, sondern im Zusammenhang damit nur von einer Leere spricht. Eine , seichte' Beziehung geht sie auch mit allen Männern ein, über die sie erzählt: Sie erinnert sich an ihren Bekannten Harold und an seine gute Küche, erwähnt ihren amerikanischen Impresario Paul und seine köstlichen Soßen und nennt ihren Freund Samuel und das ihr von ihm empfohlene Kleid. Charlotte fügt jedem dieser Männer eine gewöhnliche, als weiblich geltende Tätigkeit hinzu, wodurch die Verweiblichung der Männer erfolgt und wodurch sie die Position eines Mannes einnimmt. Dabei spielt die Tatsache, dass sie nur Brüder hatte und unter Männern herangewachsen ist, in ihrer Vermännlichung eine nicht zu verkennende Rolle: Die männliche Gesellschaft entkleidete sie ihres Weiblichen, in das sie die Männer, denen sie später begegnet, ,einkleidet'. Von den genannten Männern hebt sich der Schriftsteller Adam $a b$, der sie für die schönste Frau der Welt hielt und ihretwegen beabsichtigte, Selbstmord zu begehen. Dieser Selbstmord ist mit einer geschlechtlichen Verwirrung auszulegen: Indem Adam Charlotte als eine schöne Frau betrachtet, zeigt er zwar ein reges Interesse für sie als Frau, es wird aber von Charlotte gedämpft, weil Adams Werben um sie aus ihrer männlich gefärbten Sicht wohl einen homosexuellen Charakter hatte. Dafür spricht auch ihr emotioneller Abstand von ihrem Ehemann, der eine geschlechtlich gleiche, fast symmetrisch bestimmte Position aufweist. Ohne Eifersucht akzeptiert Charlotte eine Geliebte ihres Mannes (Maria), und ohne Gewissensbisse erkennt sie sich das Recht auf einen Geliebten (Martin) zu. Diese Gleichheit, auf die auch indirekt die ersten Silben der Namen der Geliebten hinweisen, manifestiert sich auf der beruflichen Ebene: Galt er als einer der größten Architekten, so ist Charlotte eine der bekanntesten Pianistinnen. Es liegt die Vermutung nahe, dass der Weg zum Akzeptieren der Tochter über das Männliche führen kann, wenn man den positiv geprägten Ton von Charlottes 
Äußerungen über die Männer in Betracht zieht. In einer Aufwallung von Zynismus und Ärger sagt die Mutter Eva ins Gesicht, dass sie ein Junge hätte sein sollen (BERGMAN 1978:59; BERGMAN 1980:49). So würde sich Eva aus einem übersehbaren Gleichen in ein wahrnehmbares Gegensätzliches verwandeln, zumal auch die Instrumente, auf denen die Protagonisten spielen, die Gleichheit zwischen der Mutter und der Tochter fördern: Eva und Charlotte werden durch das gleiche Instrument (Klavier) charakterisiert, während Charlotte und Leonardo unterschiedliche Instrumente (Klavier und Cello) zuzuschreiben sind.

Die Momente nach Charlottes Abreise mit ihrem Geliebten, in denen Eva ihre Zeit äußerst intensiv mit dem Vater und den Onkeln verbringt, und besonders die Augenblicke, in denen sie bei ihrem Vater weint, können als Versuche gelten, sie zu vermännlichen und als Junge auf die Welt kommen zu lassen (BERGMAN 1978:59f.; BERGMAN 1980:50). Der vom Vater ausgehauchte Rauch ist als eine Art Schoß zu betrachten, in den die Tochter zurückkehrt, um kompensatorisch eine stärkere Nähe zum Vater im ontologischen Sinne herzustellen. Die ontische Nähe zwischen Eva, ihrem Vater und ihrem Onkel erinnert an die Position der von ihren Brüdern vermännlichten Charlotte und wird durch das Ticken von drei verschiedenen Uhren wiedergegeben (BERGMAN 1978:60; BERGMAN 1980:50). Das Ticken der Uhren, deren Asynchronität die harmonische Koexistenz der ihre Individualität bewahrenden Menschen bedeutet und deren Synchronität den Verlust der persönlichen Identitätsautonomie infolge der Verschmelzung der Menschen zu einem Dasein symbolisiert, spielt darauf an, dass es zwei nahe Bande zwischen dem Kind und den Eltern gibt - die Bande des Blutes und die Bande des Geistes. Es scheint, dass die ,verstreuten', getrennt existierenden Körper des Kindes und der Eltern - in einem weiteren Umfang auch der Körper des Onkels als eines Familienangehörigen - wieder zusammenwachsen, wodurch ein dreiteiliger Organismus entsteht, in dem die für die ontische Nähe stehenden Blutsbande enger geknüpft werden, um die die ontologische Nähe vertretenden Geistesbande zu stärken. Indem Charlotte ihre Töchter verstößt, zerstört sie die zwischen den Körpern bestehende Harmonie, weil sie sie nach der Geburt nicht nur von ihrem Blutkreislauf, sondern auch von dem Geisteskreislauf abgeschnitten hat. Wenn der vordere Teil des Frauenkörpers (Bauch) auf die Entstehung eines neuen Lebens hinweist, hängt der hintere Teil des Frauenkörpers (Rücken) mit dem Tod zusammen: Gibt die Mutter dem Kind das Leben im Akt der Geburt als einer physischen Trennung, so tötet sie sein Leben, wenn sie ihre geistigen Bande zu dem Kind zerreißt, was sich in Charlottes Rückenschmerzen äußert, die auf einem 
harten Bettgestell vergehen, in dessen Bild die Härte des Sargbodens mitschwingt. An den Tod heran wird aber nicht nur die Mutter, sondern auch das Kind geschoben. Wenn Charlotte ihre jüngere, verkrüppelte Tochter Helena, die seit zwei Jahren bei Eva wohnt, in den Armen hält, lassen die Schmerzen von Helena nach, wodurch sie genest und das Gespenst des Todes sich verflüchtigt. Daraus geht hervor, dass die ontische Nähe notwendig ist, um die ontologische Nähe zu reanimieren. Dass die Geistesbande im Hinblick auf ihre die Identität des Menschen mitbestimmende Funktion existenznotwendig sind, bezeugt der im Alter von vier Jahren ertrunkene Sohn von Eva, Erik. Obwohl er im ontischen Sinne nicht mehr lebt, existiert er ontologisch in der Welt von Eva weiter.

Die Liebe, die als Realisierung der ontologischen Nähe aufzufassen ist und die zwischen Leonardo und Helena aufzugehen begann, veranschaulicht die Genesung eines Körpers, dem dieses Gefühl bisher vorenthalten blieb. Die Krankheit von Helena verging, nachdem sie und Leonardo sich ineinander verliebt hatten, kam aber zurück, als Charlotte sie voneinander trennte: Sie kehrt mit Eva vom Spaziergang zurück und sieht Helena und Leonardo apathisch in den entgegengesetzten Ecken des Zimmers sitzen. Die ontische Ferne spiegelt die ontologische Ferne der beiden wider, der sie entgegenzuwirken versuchen, worauf die Tränen von Leonardo hinweisen: Der Rückzug der Körper, deren Nähe die geistige Zugehörigkeit zum Ausdruck bringt, ergibt die Tränen, die von den gegenüberliegenden Zimmerecken aufeinander zuströmen und die als ,Leiber' des Wassers darauf abzielen, sich zusammenzumischen und die die Tränen vergießenden Körper wieder zu verbinden. Unter diesen Umständen kommt auch dem Alkohol eine wesentliche Rolle zu, der von Leonardo als ein taktisches Mittel gegen das apodiktische Wesen von Charlotte verwendet wird und der ihre Manipulationsmechanismen transparent macht. Leonardos Zustand des Betrunkenseins ist einerseits als der Versuch zu verstehen, die gegen die Gefühlsspontaneität verstoßende Steifheit des Erwachsenen aufzuheben und so die Auflockerung des verkrampften Organismus von Helena zu provozieren. Andererseits entfernt er sich durch das Betrunkenensein vom Erwachsenen und nähert sich dem Kindischen, in das Helena von der Mutter brutal eingepfercht wurde, um sie von Leonardo zu separieren (BERGMAN 1978:80f.; BERGMAN 1980:68f.). Charlotte setzt die Bindung zwischen Helena und Leonardo außer Kraft, indem sie auch ihn subordinativ behandelt, wodurch sie die Kontrolle über die beiden übernimmt und sich das Recht auf die Entscheidung über ihr Schicksal anmaßt (BERGMAN 1978:82; BERGMAN 1980:70). Auf den herablassenden Ton von Charlotte reagiert Leonardo nervös und unhöflich, weil 
seine sich in der Liebe ausdrückende Freiheit in das Joch eines anderen Menschen eingespannt wurde. Deshalb sucht er Zuflucht in der Arbeit und im Betrunkensein. Das Betrunkensein hat aber jetzt eine andere Rolle: Es hilft ihm, die Unerträglichkeit der Situation zu betäuben und seine Aufmerksamkeit von der Demütigung abzulenken.

Regnete es, als Charlotte das Haus nach drei Tagen verließ, so regnet es auch, als Leonardo Helena über seine Abreise informiert. Im ersten Fall überschwemmt der Regen den schon wegen der irritierenden Bemerkungen von Charlotte schaukelnden Familienkreis, dessen Bild im Kontext des bald in Schnee umschlagenden Regens in Charlotte keine mythologische Seejungfer mehr erblicken lässt, sondern eine märchenhafte Schneekönigin, deren Schneeflocken so kunstreich sind (ANDERSEN 2003:319) wie Charlottes Musikinterpretationen und die - wie Charlotte - überall Lustbarkeit (ANDERSEN 2003:348) herrschen lässt. Im anderen Fall spült der Regen die Reste des Betrunkenseins von dem spazierenden Leonardo und bedingt seine Rückkehr zum Erwachsensein, indem er seine Haltung strafft. Das Weinen von Helena, nachdem Leonardo fortgegangen ist, kann als eine auf Selbstmord hinauslaufende Selbstüberschwemmung angesehen werden: Auf den Tod verweisen im Übrigen die zurückgekommenen Symptome der Krankheit, die die Gedanken an eine der Beweglichkeit verlustig gegangene Leiche intensivieren - die Schmerzen in der Hüfte und im rechten Bein. Es sind also keine Rückenschmerzen, wie sie wegen des Verstoßens der Kinder bei Charlotte auftraten und die in der (waagerechten) Liegeposition spürbar werden, sondern Beinschmerzen, die beim (senkrechten) Stehen zu spüren sind und jede Bewegung unerträglich machen. So gehen die Mutter und die Tochter auch in Bezug auf das Leiden, dem eine emphatisch-integrative Funktion nicht abzuerkennen ist, aneinander vorbei: Leidet die Mutter vor allem während der Nacht, die durch die Liegeposition des Menschen gekennzeichnet ist, so nimmt das Leiden der Tochter besonders am Tag zu, der vom Menschen die Stehposition verlangt. Eine andere Funktion hat der Regen, als Eva die Mutter vor dem Schlaf in ihrem Zimmer besucht. Der hörbar auf das Dach tropfende Regen, der nur einmal während des Besuches von Charlotte im Pfarrhaus erscheint, ,vertont" und markiert somit die Inversion der Rollen von Mutter und Tochter: Das Verhalten der sich auf den Schlaf vorbereitenden Charlotte ähnelt dem Benehmen des auf Nachsicht für Unfug zählenden Kindes, während der hochmütig-fürsorgerische Ton der Aussagen von Eva sie auf das Niveau der eine Strafe für den Kinderstreich erwägenden Eltern bringt (KOŁODYŃSKI 1978:22). Es hört auf zu regnen, als Charlotte nach einem Buch greift, in dem sie eine erotische Stelle liest 
(Bergman 1978:52; Bergman 1980:43). Die von dem erotischen Passus des Buches angesprochene Sexualität von Charlotte verhilft ihr zum Wiedergewinn des Erwachsenseins, für das der sexuelle Bereich eben reserviert ist. Somit wirft sie die Position des Kindes ab, was die Stille nach dem verhallenden Regengeräusch kundtut. Im Weinen der Mutter nach dem Gespräch mit Eva kurz vor ihrer Abreise aus dem Pfarrhaus ist wieder das Wasser konnotiert, dessen Strömung sie wiederholt in die Welt mit sich bringt.

Charlotte wird nicht nur die Schuld an Helenas Krankheit, sondern auch am Scheitern der Liebesbeziehung von Eva und Stefan, ihrem ehemaligen Freund, zugeschoben. Um die Tochter bei sich zu behalten, versucht sie in ihr eine Abneigung gegen Stefan hervorzurufen, indem sie seine negativen Charakterzüge hervorhebt, aus denen sie seine ganze Persönlichkeit zusammenflickt. Auf das gleiche Resultat waren auch ihre Bemühungen bedacht, Eva zur Abtreibung des gemeinsamen Kindes der beiden zu zwingen. So verhindert es Charlotte, dass das Kind ihre Beziehung mit Stefan besiegelt und dass Eva als Mutter eine gleichrangige Position gewinnt, wie sie Charlotte ihr gegenüber hat. Wenn man auf das Familienhaus von Charlotte rekurriert, kann Evas Abtreibung in einem anderen Licht gesehen werden, was das Verhalten der Mutter zwar nicht rechtfertigt, aber seine Kompliziertheit belegt:

Mor och far var framstående matematiker, de var besatta av sin vetenskap och av varandra. De var dominerande, lättsinniga och godlynta. Oss barn betraktade de med förvånad välvilja, men utan värme eller verkligt intresse. Jag kan inte minnas att någon av dem någonsin rörde vid mig eller mina bröder, vare sig med smekningar eller bestraffningar. I själva verket var jag fullständigt okunnig om allt, som hade med kärlek att göra: ömhet, beröring, närhet, värme. Det var bara genom musiken som jag fick möjlighet att visa mina känslor. (BERGMAN 1978:74f.)

Mutter und Vater waren glänzende Mathematiker; sie waren besessen von ihrer Wissenschaft und voneinander. Sie waren dominierend, leichtsinnig und lustig. Uns Kinder betrachteten sie mit wohlwollendem Staunen, aber ohne Wärme und wirkliches Interesse. Ich kann mich nicht erinnern, daß auch nur einer von beiden mich oder meine Brüder jemals körperlich berührt hätte, sei es zärtlich, sei es strafend. Ich hatte tatsächlich keine Ahnung von all dem, was Liebe bedeutet: Zärtlichkeit, Berührung, Nähe, Wärme. Nur in der Musik fand ich eine Möglichkeit, meine Gefühle zu äußern. (BERGMAN 1980:64)

Charlottes Gefühlsunvermögen hängt mit ihrer Vergangenheit zusammen, die dafür verantwortlich ist, dass sich ihre Emotionen nur im Bereich der Musik aktivieren. Die Musik hat sich als Ventil für den Ausdruck ihrer Erlebnisse 
erwiesen, wozu die Mathematik beigetragen hat, mit der sich ihre Eltern beschäftigten. Die Mathematik, die einerseits als ungewöhnliche Errungenschaft des menschlichen Geistes (KOŁAKOWSKI 2006:14) und andererseits als ein ,herzloses“ und gottloses System (KOŁAKOWSKI 2005:64) zu betrachten ist, blockierte Charlotte den Zugang zur empirischen Welt, wodurch ihr Interesse für Musik blühte. So wurde die Wissenschaft (Mathematik), die mit den Gedanken ,gespeist' wird, mit der Kunst (Musik) gekoppelt, der die Gefühle Nahrung geben. ,Kopf' und ,Herz' als Opponenten pointieren die Situation von Charlotte und veranschaulichen, wie eine in der Welt der Musik vor Emotionen strotzende Person in der Realität impotent ist. Charlottes Drängen auf Evas Abtreibung des das weibliche Geschlecht annehmenden Embryos kann aber von der Seite der Vernunft, die bei Charlotte auf dem Gebiet der Wirklichkeit von jeder Emotion gereinigt war, als Versuch ausgelegt werden, die Kontinuität der sich vererbenden Gefühllosigkeit zu unterbrechen und der Vervielfältigung des Mutter-Tochter-Koexistenzmodels vorzubeugen (BERGMAN 1978:75; Bergman 1980:64). Diese in einem sehr hohen Grade selbstreflexive Erkenntnis von Charlotte enthält die bittere Erfahrung der Aussperrung - der geschlossenen Tür, die Charlottes Mutter, nachdem sie sie auf die Welt hatte kommen lassen, einen Spalt weit öffnete, jedoch gleich wieder zuklappte, als die auf die Welt neugierige Tochter das Haus für einen Moment verließ. ,Entschärfen“ die Kindheitserfahrungen von Charlotte ihre Grausamkeit, die sie Evas Schwangerschaft entgegengebracht hat, so bekommt auch die die Zeichen der Mutterschaft verwischende und die Beziehung zu den Töchtern noch mehr abbrechende Sorge um das eigene Aussehen eine neue Optik. Wenn sie sagt, dass sie sich ungeboren fühle (BERGMAN 1978:76; Bergman 1980:65), verrät sie, dass sie so im Vorraum der Wirklichkeit steht, wie ein Kind im Schoß der Mutter von der Wirklichkeit noch getrennt ist. Als eine im Bereich der Musik versunkene Person altert sie zwar biologisch, aber ihre mentale Entwicklung steht still, weil diese nur in dem Bereich der empirischen Wirklichkeit, an die Charlotte bloß angelehnt ist, stattfinden kann. In ihrem Inneren ist die Zeit also stehengeblieben, wie der Musikbereich durch den Eindruck der Zeitlosigkeit gekennzeichnet ist. Daher verwundert es nicht, dass Charlotte ohne Uhr auskommen kann: Sie entledigt sich der Uhr, die sie von einem Verehrer als Anspielung auf ihre Unpünktlichkeit geschenkt bekam, und gibt sie Helena, die in dem von der Zeit regierten Bereich verankert ist. In der Filmfassung von Bergmans Drehbuch wird Charlottes Distanz zur Wirklichkeit noch krasser dargestellt, weil sie auf dem den Sargboden reflektierenden Fußboden liegt, dessen Härte am Tag die in der Nacht für die Rückenschmerzen wohltuende Härte des Bettgestells 
ersetzt, und über ihre Existenz nachdenkt (BERGMAN 1978a:1:09:161:13:16). Dadurch wird unterstrichen, dass sie als tot geboren wurde und nie in die zeitbestimmte Wirklichkeit vorgedrungen ist. Insoweit Eva die geistigen Bereiche von den Innenwelten der Menschen ,zusammenfügen“ konnte, überschreitet das Zusammensetzen der sinnlich wahrnehmbaren und physisch konkretisierten Teile der Menschen die Möglichkeiten von Charlotte (BERGMAN 1978:76; BERGMAN 1980:65f.). Charlotte fehlt es also am Sinn für Wirklichkeit. Dafür spricht auch die Tatsache, dass sie 20 Jahre lang keinen Schnupfen hatte, oder die Brille, derer sie sich nur dann bedient, wenn sie von den Lebensumständen gezwungen wird, einen Blick auf die Wirklichkeit zu werfen. Beachtenswert erscheint die Szene, in der Charlotte Helena ihre Brille abnimmt und sie sich aufsetzt. Mit dieser Tat demonstriert sie ostentativ ihre Absicht, der Tochter ihre Aufmerksamkeit zu widmen, wodurch angedeutet wird, dass sie sich in Helenas Lage hineinzuversetzen versucht. Das Brillenglas erweist sich jedoch nicht als Mikroskopglas, mit dem sie in das Innere von Helena um einer besseren Erkenntnis der Tochter willen hineinschauen könnte, sondern als ein Fernglas wie das, mit dem Coppola in E. T. A. Hoffmanns Sandmann Nathanael die Augen abnimmt und sie in Olimpia einsetzt (HOFFMANN 2005:28f.), wodurch sein Inneres in ihr Inneres implantiert wird und wodurch er sich in Olimpias Körper selbst begegnet (HOFFMANN 2005:32f.). Helenas Inneres wird aber nicht in das Innere von Charlotte einmontiert, was einen Einblick in die Seele der Tochter nach sich ziehen könnte, sondern Charlotte wird auf ihr eigenes Inneres zurückgeworfen, weil die Brillengläser von Helena, auf deren Augen die Linsen zugeschnitten waren, der Mutter ein verschwommenes Bild der Wirklichkeit geben mussten und so nur zur Projektionsfläche ihres Ichs wurden. Auf diese Weise dient der Mutter Helenas Brille als Schutzbrille gegen die eigene Tochter. Dass Charlotte das gewöhnliche Leben, das ihr nie zuteil wurde, aus der Ferne beobachtet, wird in einer der letzten Handlungssequenzen des Drehbuchs resümiert (BERGMAN 1978:88; BERGMAN 1980:75). Charlottes Distanz zur Wirklichkeit geht mit ARTHUR SCHOPENHAUERs (2001:38) Weltauffassung einher, die er mit der Metapher des Schlosses ausdrückt, das der Mensch nie betreten, sondern immer nur umkreisen kann. Wenn sich Charlotte in ihr von der Fassade des Körpers gegen die Außenwelt hermetisiertes Inneres einschließt und wenn die Welt nach dieser Auffassung ohnehin keinen Menschen in ihr Inneres eindringen lässt, ist zu schlussfolgern, dass die Existenz von Charlotte weniger scheinbar ist als die der anderen, die sich umsonst die Mühe geben, in die Mitte der Welt zu gelangen. 
Die Periode der Mutter-Tochter-Relation, die nach Charlottes Karrierezusammenbruch eintritt und die mit dem ganzen Ablauf des im Roman von Jelinek thematisierten Mutter-Tochter-Verhältnisses besonders stark korrespondiert, entblößt die Misogynie der Mutter (ŻURAWIECKI 2007:52) und verdeutlicht ihre an Passion grenzende Dressur der Tochter:

Du förklarade för mig att jag var stor flicka och att jag inte skulle gå i långbyxor och tröja utan i klänningar som du lät sy eller sydde själv utan att fråga vad jag tyckte och jag kunde inte säga nej, eftersom jag inte ville göra dig ledsen. (BERGMAN 1978:67)

Du erklärtest mir, ich sei ein großes Mädchen und dürfe nicht mehr in Hosen und Pullover herumlaufen, sondern müsse Kleider tragen. Die wurden genäht, oder du nähtest sie selbst, ohne mich je zu fragen, ob sie mir gefielen, und ich konnte nicht nein sagen, weil ich dich nicht traurig machen wollte. (BERGMAN 1980:57)

Dieses Zitat zeigt, wie Charlotte Eva mit ihrer Identität ,kolonisierte‘. Es gilt zu bemerken, dass Charlotte die Identität von Helena, ihrer anderen Tochter, nicht entsprechend massakrierte, was mit ihrer Verkrüppelung verbunden sein kann, die sie vor der Mutter geschützt hat. In Helena hat Charlotte eine Person gesehen, die wegen ihrer Krüppelhaftigkeit wie sie weit von der Wirklichkeit entfernt ist. In dieser situationsbezogenen Verwandtschaft ist auch der Grund dafür zu finden, warum Charlotte Helena zu einer Ersatzmutter erhebt, worauf die in den Regieanweisungen beschriebene, Rückkehr'von Charlotte in Helenas Schoß deutlich hinweist (BERGMAN 1978:85; BERGMAN 1980:72). So wie die kakophonischen Laute, die Helena aus ihrem Inneren herausbringt, und die euphonischen Klänge, die Charlotte ihre Klavier spielenden Finger erzeugen lässt, zusammengehören und die Welt des Hörbaren wechselseitig ergänzen, so bestimmt der eingeschränkte Zugang der beiden Frauen zur Wirklichkeit - wegen der physischen Verkrüppelung von Helena und der emotionellen Verkrüppelung von Charlotte - ihre Zugehörigkeit zueinander. Dass diese Gleichstellung wirklich besteht, sieht man in dem Moment, in dem sie zugrundegerichtet wird: Als Charlotte das Pfarrhaus verlässt und in ihre Musikwelt zurückfährt, beginnt sich der Körper von Helena konvulsiv zusammenzuziehen und immer mehr, bis zu einer lebensgefährlichen Erstarrung, zu versteifen. Wurde Charlotte von ihrer Mutter weggestoßen, so ist Helena bereit, sie anzunehmen: Indem sie die Arme ausstreckt, öffnet sie die einst von Charlottes Mutter geschlossene Tür. Die unterschiedlichen Einstellungen von Helena und Eva zu Charlotte werden durch ihre gegensätzlich verlaufenden Bewegungen zum Ausdruck gebracht, die damit enden, dass die Töchter mit der Mutter zusammenprallen. Eva assoziiert die Mutter mit einem Monster, das das Kind überfällt (BERGMAN 
1978:27; Bergman 1980:23). Dieser Erinnerung an die Mutter widerspricht Charlottes Traum, in dem Helena die Mutter überfällt (BERGMAN 1978:52; BERGMAN 1980:43). Mit dem Bild der Charlotte überfallenden Helena wird der Rollenwechsel - Charlotte als Tochter und Helena als Mutter - antizipiert und der Austausch von Charlottes hassorientierter Existenzrichtung gegen einen liebeorientierten Existenzweg für möglich erklärt.

Auch bei Jelinek wird die Tochter von der Mutter annektiert, was die Szene ähnlich wie bei Bergman - mit dem Kleid veranschaulicht. Die Mutter greift ein, als Erika sich ein neues Kleid kauft, weil sie nicht die Tochter, sondern sich selbst das Kleid anhaben sieht:,So versucht die Mama heute ihrer Tochter das neue Kleid aus den zusammengekrampften Fingern zu winden [...]. Loslassen, sagt die Mutter, gib es her!“ (JELINEK 2005:11) Die Mutter erhält die Dominanz über die Tochter, indem sie ihre Garderobe kontrolliert, was beweist, dass die Tochter zwar als ein separater, aber integraler Teil der Mutter gilt. Da der Körper der Tochter nur ein , abgesplitterter ‘ Teil der Mutter ist, keimt Erikas Unabhängigkeitsidee ohne physische Absonderung, also wider die existenzialistische Weltanschauung, nach der die Existenz die Voraussetzung für die Essenz ist (SARTRE 1998:23). Die Tochter setzt nicht ihren Körper, der der Mutter angehört, sondern ihren Geist in das ohne eine Person leichenhaft anmutende Kleid ein, denn sie stellt sich lediglich vor, wie sie im Kleid aussieht - eine Vorstellung, die sich aus der auf dem neutralen Boden des Kleidergeschäfts gewonnenen Erinnerung entwickelt (JELINEK 2005:13f.). Das Handeln der Mutter, die ihre Wut an den Kleidern auslässt, hängt mit der Reaktion auf den Verstoß der Tochter gegen die von ihr geregelte Ordnung zusammen, die die Verstrickung von Erika in die Form der Mutter plakativ vor Augen führt: Verletzt Erika die Konstruktion der von der Mutter regulierten Ordnung, so greift die Mutter ein Kleid von Erika an, das die Tochter vertritt und als ihre, Fassung ' fungiert:

Die Mutter betrampelt das Kleid mit ihren Hausschuhen [...]. Im Endeffekt sieht das Kleid nur etwas zerknittert aus. Daher zieht die Mutter mit einer Küchenschere ins Feld der Unehre, um dieser Schöpfung [...] den letzten Schliff zu versetzen. [...] Die Mutter säbelt jetzt die Bordüre am Ausschnitt und die anmutigen Puffärmel [...]. Dann schneidet sie Überreste des angekrausten Rocks vom Oberteil herunter. [...] (JELINEK 2005:154f.)

Indem die Mutter das für Erika als Para-Haut ihres Körpers funktionierende Kleid rituell zerschneidet, zerstückelt sie das Surrogat des Körpers, an dem es Erika mangelt. Mit der Rückkehr der Tochter nach Hause wird die gebrochene Ordnung der Mutter wiederhergestellt: Die Mutter inkorporiert den Geist von Erika, was letztendlich in dem Bett erfolgt, in dem die beiden 
zusammen schlafen und wo sie und die Mutter ,zusammengestellt' werden. Diese Inkorporierung kann mit dem künstlichen Gebiss parallelisiert werden, das sich die Mutter jeden Morgen in ihren Mund steckt, wenn sie nach dem Schlaf der Wirklichkeit entgegentritt. Die von Erikas Mutter zerschnittenen Kleider korrespondieren mit den von Evas Mutter genähten Kleidern in Bergmans Werk: In der ersten Situation wird der Ansatz des souveränen Körpers von Erika eliminiert; in der zweiten Situation dagegen kommt es auf die Eliminierung des aus Eva auftauchenden Mannes an, an den Charlottes Tochter wegen der getragenen Hose zu erinnern begann und den Charlotte in ihr ,zunäht', um ihre eigene, durch die Vermännlichung erreichte Hegemonie zu bewahren.

Spielen die Männer - der Vater und der Onkel - im Leben von Eva bei Bergman eine rettende Rolle, weil sie ihre Einsamkeit abbauen, so kommt auch den in der Umgebung von Erika bei Jelinek erscheinenden Männern - dem Vater und Klemmer - eine potentiell erlösende Funktion zu. Charlottes Geliebter schützt Eva vor dem Liebe vortäuschenden Hass der Mutter dadurch, dass er Charlotte zu sich ruft und sie so von zu Hause wegbringt; Erikas Vater dagegen scheint den Wahnsinn, in den Erika unter dem Einfluss der Mutter zu verfallen begann, von der Tochter zu ,übernehmen'. Er lässt sie aufrecht in der Mitte der Wirklichkeit stehen, die im Feld zwischen seinem von der totalen Normenauflockerung fundierten Wahnsinn und dem von der totalen Normenankurbelung gestifteten Wahnsinn der Mutter entsteht und die insofern normal wirkt, als ein Wahnsinn durch einen anderen ausgeglichen wird. Davon, dass Erika sich ihrer Lage bewusst ist, zeugen die handgreiflichen Situationen, an denen die Mutter und Erika teilnehmen und die - anhand der drei Mutter-Tochter-Schlachten - verfolgen lassen, wie Erika diesen eigenen Bereich in Anlehnung an die Aktivierung ihres sexuellen Triebs allmählich verbreitert. Nachdem die Mutter in ihren Kleidern herumgewühlt hat, wird sie im ersten Kampf von der Tochter angegriffen und am Kopf geschlagen, wodurch Erika zum ersten Mal verrät, dass sie sich von der Mutter geistig nicht entmündigen lässt, obwohl ihre Person völlig in der Mutter ,lagert‘. Dass der Kampf um mehr Raum für den zusammengepressten Geist der Unabhängigkeit auf den Kampf gegen das Gedränge im physischen Sinne übertragbar ist, zeigt auch der Film Frances (1982) sehr deutlich, der die gleiche Problematik aufnimmt: Die von der Mutter zur Fortsetzung der Karriere eines Hollywood-Filmstars gezwungene Frances Farmer schafft sie unter Gewaltanwendung zur Ausgangstür, was eine Antwort auf die Tat der Mutter ist, die die Tochter gegen die Wand schleudert, um sie so physisch in die Filmbranche zurückzuschleudern 
(CLIFFORD 1982:1:34:29-1:38:04). Als Erika ein weiteres Mal verspätet zu Hause erscheint, ereignet sich die zweite Prügelei, die jetzt von der Mutter nicht nur provoziert, sondern auch begonnen wird. Das Ende der beiden Schlägereien zwischen Erika und ihrer Mutter ist jedoch unterschiedlich. Der erste Kampf endet mit Aussöhnung (JELINEK 2005:11f.); diese wird durch das gemeinsame Ausbrechen in Tränen besiegelt, die ihre Körper nass zu machen und leimartig zu erweichen scheinen, wodurch der Eindruck entsteht, dass die Mutter und die Tochter ,ineinandergeklebt' werden. An der völligen Aussöhnung nach dem zweiten Kampf dagegen muss gezweifelt werden (JELINEK 2005:161). Die Träume, die Erika erwähnt, beziehen sich nämlich auf ihren Besuch im Prater, wo sie dem Geschlechtsverkehr einer Prostituierten mit einem Ausländer zusieht. Erikas Tendenz, eine eigene, von der Mutter unabhängige Form herauszubilden, ist von dem gleichseitigen Dreieck als der einfachsten ein Inneres besitzenden Figur abzulesen, die die Mutter aus der Bettdecke formt. Darin wird das Dreieck widergespiegelt, das Erika mit dem sich im Prater-Park liebenden Paar bildet. Wenn man dem Ziel von Erikas Eskapaden in den Prater-Bezirk Rechnung trägt, wird sichtbar, dass der Weg zu einer eigenen Form über die Sexualität führt: „Sie allerdings strebt keinen Verlust ihrer Person an, sondern eher: Gewinn. [...] Etwas zieht Erika saugend in diese Landschaft hinein, und nicht zum ersten Mal heute.“ (JELINEK 2005:139) Die Form, deren Spender - wie auch im Falle des die Bedeutung eines Begriffs umhüllenden und sie so aus dem Inneren des Menschen nach außen bringenden Wortes - die Außenwelt ist, kann nicht aus der Strecke geschöpft werden, die die zwei Punkte (Mutter - Tochter) verbindet und die überhaupt keine ein Inneres aufnehmende Fläche hat, sondern ist aus dem Dreieck abzuleiten, das die drei Punkte (Mutter Tochter - Mann/Ausländer) abstecken und das schon sein eigenes, zu dem menschlichen Inneren ein Analogon bildendes Inneres aufweist. In der Filmfassung des Romans - La Pianiste [Die Klavierspielerin] (2001) - wird Erikas Suche nach der Form derart hervorgehoben, dass sich die Prostituierte und der Ausländer in einem Auto lieben (HANEKE 2001:0:48:48-0:50:45), wodurch das Planimetrische des Dreiecks ins Stereometrische des Autos übergeht, dessen Volumenbeschaffenheit noch mehr mit dem menschlichen Körper verwandt ist. Um der harmonischen Entwicklung des Kindes und der ungestörten Adoleszenz willen soll ein Punkt des Dreiecks vom Vater gebildet werden, der die Mutter-Kind-Zweisamkeit aufsprengt und die Konstituierung der eigenen Autonomie an der Grenze, an der sich das Weibliche der Mutter und das Männliche des Vaters zusammenreiben, ermöglicht (GALLAS 2007:101). Da der Vater an Erikas Erziehung wegen der 
dominierenden Mutter nicht teilnahm, versucht sie den vom Vater zu besetzenden Punkt des Dreiecks mit anderen Männern zu ,flicken“ - sei es mit dem sich im Park mit der Prostituierten liebenden Ausländer oder mit dem zu ihren Schülern gehörenden Klemmer. Die Bekanntschaft mit Klemmer, mit dem sie und ihre Mutter ein länger währendes Dreieck formen und der sich in ein anonym anmutendes männliches Ich am Ende des Werks verwandelt (CHOŁUJ 1995:146) - ähnlich wie die Mutter von Erika, die keinen sie von der Umgebung abhebenden Vornamen (MAJKIEWICZ 2008:95) hat und das ganze Werk hindurch als eine objektiv wirkende Macht (ZEYRINGER 2001:187) erscheint -, läuft in erster Linie nicht auf ihre sexuelle Befriedigung, sondern auf die Steigerung ihres sexuellen Potentials hinaus, das sie im dritten Kampf gegen die Mutter einsetzt, als sie sie im Bett missbraucht (JELINEK 2005:238f.). Einerseits lässt das Bett Erika als ein mit ihrer Mutter schlafendes, während der Geburt bloß auf die Rückseite ihres Bauchs verlegtes Kind erscheinen. Andererseits ruft dieses Möbelstück die Assoziation mit dem Vater hervor (MAYER / KOBERG 2006:114), dessen Platz Erika im Bett neben der Mutter einnahm, als er nach seinen Aufenthalten im Sanatorium und im Irrenhaus starb. Schlüpfte Charlotte bei Bergman abwechselnd in die Rolle eines Mannes oder einer Frau, so weisen sowohl Erika als auch ihre Mutter gleichzeitig männliche und weibliche Züge auf. Indem Erika die Arme der Mutter auseinanderspreizt, kehrt sie metaphorisch in den Schoß der Mutter zurück - die Bewegung, mit der Helena in Bergmans Werk ihre Mutter in den Schoß eingeschlossen hat. Erika überfällt den Körper der Mutter als eine an ihr, verhakte“ Frau, reißt aber ihren eigenen Körper schon als ein Mann ab, in dessen größeres Freiheitsgebiet in der Gesellschaftshierarchie sie sich so zu ,schmuggeln“ versucht (SUGIERA 1997:177) und zu dem sie sich designiert, wenn sie die Vagina-Gegend der Mutter stürmt. Davon, dass der sexuelle Akt als eine Prozedur fungieren kann, die auf die Zerstörung einer die Unabhängigkeit begrenzenden Person abzielt, zeugt das - auch inzestuöse - Motiv im Film The Damned [Die Verdammten] (1969), wo der Sohn die Mutter vergewaltigt (VISCONTI 1969:2:07:23-2:10:05) und sich so an ihr für ihre Unterordnungsversuche rächt, die auf den in der Marlene-Dietrich-Travestierung gipfelnden Frauenverkleidungen beruhen, wodurch er entmännlicht und der gesellschaftlich stärkeren Position des Mannes beraubt wurde. Martin aus Viscontis Film lässt an die Gestalt von Erikas Vater denken, der seinen „männlichen“ Geist aufgab (HAMMER 2007:37) und - ähnlich wie Eva in Bergmans Text - in die ungeregelte Wirklichkeit des Wahnsinns Zuflucht nahm, als seine Frau die sich in den Direktiven des Handelns ausdrückende Rolle des Mannes an sich 
riss und als er die ihm in der geregelten Wirklichkeit übriggebliebene, sich in den Direktiven des Aussehens äußernde Rolle der Frau ablehnte. Zwar geht der Akt der perversen Sexualität, den Erika gegen ihre Mutter vornimmt, wegen ihres weiblichen Geschlechts nicht mit dem Koitus aus, was bei Visconti der Fall ist, aber dadurch, dass Erika ihren Körper an den Körper der Mutter dichter als je drückt, hofft sie von der Mutter abzuprallen und mehr Abstand zu gewinnen. Erikas Streben nach Distanz ist weiterhin aus einer psychoanalytischen Perspektive zu sehen, die die Schamhaare der Mutter mit den Schamhaaren der mit Charlotte zu identifizierenden Romanprotagonistin aus Adams Buch bei Bergman verbinden lässt: Bezieht man die die Vagina verbergenden Schamhaare auf die Symbolik eines das Unbekannte verbergenden Waldes, dessen erfolgreiches Durchqueren die Lösung eines Problems markiert und den Menschen mit einer höheren Entwicklungsstufe des Ichs ausstattet (BETTELHEIM 1980:109), so ist der Penetrationsakt als ein Übergang auf die andere Seite des Partners zu verstehen, wodurch ein Ich über das andere Ich hinweggesetzt wird. Das Ablassen von der Mutter fällt Erika umso leichter, als dem sexuellen Angriff auf die Mutter der Besuch von Klemmer in ihrer Wohnung vorangeht, in der die Konstellation MutterTochter zerbrochen (LIEBRAND 2006:33) und mit Klemmer als einem Teil dieser Konfiguration reorganisiert wird, weil der sich zwischen Erika und ihm entwickelnde Bereich des Sexuellen dieselben Komponenten wie der Erika und ihre Mutter bestimmende Bereich der Musik beansprucht, nämlich den Körper und den Geist. Während die Körper von Erika und Klemmer in der sexuellen Situation gegenseitig ihre eigenen geistigen Sphären aktivieren und die eigenen Identitätsdimensionen enthüllen, werden Erikas Geist und Körper von der sich auf die Musik beziehenden Identitätsbeschaffenheit der Mutter beschlagnahmt: In der Musik, die der bürgerlichen Ideologie einverleibt (JANZ 1997:229) und in der Ideologisierung der Heimat ausgenutzt wurde (SEBALD 1995:14), erblickte die Mutter die Möglichkeit der Nobilitierung in der Gesellschaft; in ihrer Tochter dagegen sah sie die Chance, ihre Träume - wenn nicht als Klavierspielerin, dann wenigstens als Klavierlehrerin am Wiener Konversatorium - zu verwirklichen, wodurch ihr Egoismus entlarvt wird, der mit kleinbürgerlicher Selbstzufriedenheit (JABŁKOWSKA 2006:274) imprägniert ist und von neurotischer Soziophobie (SCHMID-BORTENSCHLAGER / SCHMID 2006:264) legitimiert wird. Davon, dass der Körper der Tochter als ,Anbau' des Körpers der Mutter funktioniert, zeugt das Verhältnis Erikas zu ihrer Körperlichkeit vor dem Hintergrund ihrer Sexualität. Die Szene, in der Erika mit ihrem Cousin ringt, reflektiert ihre Kämpfe mit der Mutter. Im Gegensatz zum kämpferischen Ringen mit 
der Mutter hat das Ringen mit dem Cousin den Charakter eines Spiels, in dem sich ihr Körper nicht wie mit dem der Mutter antagonistisch reibt und in ihre Körperlinie ,einhakt‘, sondern sich auf seinen Körper symbiotisch abstimmt und an seine Körperlinie anpasst. Besonders der Penis des Cousins, der in der Gestalt des von ihr betrachteten und „ein wunderbares Universum“ (JELINEK 2005:61) chiffrierenden Tannenzapfens noch einmal auftaucht, weckt ihr großes Interesse, weil sie in ihm ein Werkzeug erblickt, das sie aus dem Körper der Mutter so herauszieht, wie sie sich einst dank ihm im Schoß der Mutter befand (JELINEK 2005:46). Das Spiel mit dem Cousin findet im Spiel mit der Rasierklinge seine Fortsetzung (JELINEK 2005:47): Die Personifizierung der Klinge und die auf den Geschlechtsverkehr hinweisende Konnotation ihrer Verwendung lassen die Vermutung naheliegen, dass Erika nach einer Körperstelle sucht, die sie anschneiden kann und von der aus sie ihren Körper vom Körper der Mutter abzuschneiden beginnt. Die Eingriffe, mit denen Erika Öffnungen im Körper macht und die einem Deflorierungsakt ähneln (JANZ 1995:76), sind nicht als Ersatz sexueller Tätigkeiten zu betrachten, sondern visieren ein rein existenzielles Ziel an: Mutterentfernung statt Entjungferung. Dies ist um so plausibler, als Erikas Körper abgerundet und abgeglättet wirkt, weil sich ,kein Haar“ an ihr hebe (JELINEK 2005:106). Dadurch lässt sich Erikas Körper mit einer Zyste vergleichen, die am Körper der Mutter haften bleibt und die physisch nicht selbständig funktioniert, weil der Körper der Mutter alle lebensnotwendigen ,Öffnungen' hat und alle lebensnotwendigen Aufgaben realisiert. Dass Erikas ,Öffnen` des Körpers in keinen sexuellen Kontext gehört, belegt ihre Bekleidungsweise, die jeden von ihrem Körper ausgestrahlten Reiz erwürgt (JELINEK 2005:48f.). Das karierte Muster des Rocks hebt ihre von der Mutter vollzogene Vergitterung hervor und ruft die Assoziation mit den Gittern von Helenas Bett wach, wobei die Gitter bei Bergman eine die Mutter von der Tochter separierende Funktion haben, während die Gitter bei Jelinek desintegrativ wirken, weil sie die Mutter und die Tochter in einen gemeinsamen, immer neue Missverständnisse hervorrufenden Existenzbereich einschließen. Auch Erikas Besuch in der Peep-Show-Kabine bestätigt die Diagnose, dass ihr Kontakt mit der Außenwelt nur mittels der zum Empfang der Reize fähigen Mutter erfolgt (JELINEK 2005:55) und dass sie über das Sexuelle in sich anzukommen versucht (JELINEK 2005:79). Ihre Scheu vor allen, auch zufälligen Berührungen ist darauf zurückzuführen, dass sie so auf die körperliche Grenze der anderen stößt, wodurch ihr immer wieder zu Bewusstsein gebracht wird, dass sie keine eigene Körperlinie hat. Die Abstumpfung gegen die Berührung verleitet sie dazu, ihre Vagina mit der Klinge zu vergrößern (JELINEK 2005:90). 
In diesem Handeln, das an eine Szene im Film Viskningar och rop [Schreie und Flüstern] (1972) von INGMAR BERGMAN erinnert, geht es deutlich um den Versuch, sich von dem Körper der Mutter zu trennen. Verletzt sich Karin in Bergmans Film mit einer Glasscherbe an der Vagina, um den einzigen, sich in den sexuellen Kontakten äußernden Bindungsfaden mit ihrem verhassten Mann Frederik zu zerreißen und den Geschlechtsverkehr zu verhindern (BERGMAN 1972:0:56:04-0:58:57), so zielt Erika darauf ab, ihren ganzen, zur Vagina gemachten Körper von der Mutter ab- und ihn Klemmer zuzuwenden (CORNEJO 2006:163). Die Vagina, wo der Vorgang von Erikas Extraktion aus dem Körper der Mutter beginnt, scheint nämlich die geeignetste Stelle zu sein, weil die Mutter als heterosexuelle Person an diesem Körperteil der Tochter am wenigsten interessiert ist. Mit der Trennung von der Mutter hängt Erikas Brief an Klemmer zusammen, in dem sie ihre sexuellen Erwartungen darstellt (JELINEK 2005:218f., 227). In diesem Brief, in dem das Bild des Erika aus dem Mutter-Block hauenden und sie so mit dem Tastsinn ausstattenden Klemmer von dem Bild des eine Frau aus einem Steinblock hauenden und sie später mit seinen Gefühlen belebenden Pygmalion (OVID 2004:301-303) überlagert wird, beharrt Erika darauf, dass ihr Körper fest umbunden wird. Dadurch entreißt sie ihren Körper dem Körper der Mutter, der sich automatisch außerhalb der Schnüre befindet, und bindet ihn an ihren eigenen Geist. So geht die Tochter der Mutter endgültig verloren - ein Verlust, der mit der Schwärze des für die sexuellen Tätigkeiten von Erika gewählten Unterkleides angedeutet wird, das eher die Trauer der Mutter um die aus ihr „ausgebrochene“ Tochter symbolisiert, als einen symbolischen Tod der Mutter bedeutet (PEŁKA 2006:245), wenn man darauf rekurriert, dass die Tochter nach dem Geschmack der Mutter angezogen wird. Die von Klemmer zu bewerkstelligende Umbindung ist mit der Entbindung gleichbedeutend, die ihre Mutter viele Jahre nach der Geburt zu Ende führt.

Der Prozess der physischen Trennung Erikas von ihrer Mutter setzt in der Wohnung der beiden ein, in die Klemmer eingeladen wurde und in der Erika ihm ihre sexuellen Begierden darlegt. Ein wichtiger Schritt auf dem Weg zur physischen Unabhängigkeit Erikas ist das Manöver von Klemmer, der die Kommode an die Tür schiebt, um sich mit Erika zu verbarrikadieren und der Mutter den Zugang zu verwehren. Dass die Mutter in dieser Situation Alkohol zu trinken beginnt, beweist ihren Schmerz, der von der physischen Abkehr der Tochter von ihr verursacht wird und den sie so betäubt, wodurch sie sich als Leidende Leonardo aus Bergmans Werk gleichstellt. Die Mutter versucht Erika noch auf ihre Seite zu ziehen, indem sie den die beiden 
integrierenden Fernseher äußerst laut stellt, aber sie kapituliert bald und senkt die Lautstärke wieder. Die Mutter ist nicht mehr imstande, die Tochter mit der Fernsehwelt über die versperrende Kommode hinüberzulocken. Zwar standen sie sich während des Fernsehens ontisch nah, aber in ontologischer Hinsicht waren sie weit voneinander entfernt, weil sie im Leben der auf dem Bildschirm gesehenen Gestalten schwelgten; dies bestätigt der Moment, in dem das Schluchzen einer Familie im lautlos gestellten Fernseher mit dem Heulen der Mutter vertont wird: Für Erika bildet die fiktive Fernsehwelt keine Konkurrenz zu der endlich zu gewinnenden Autonomie des Körpers, die dank Klemmer in Erfüllung gehen kann. Mit der Szene, in der Klemmer zum ersten Mal in Erikas Wohnung kommt, korrespondieren die Ereignisse, die während seines zweiten Besuches in ihrer Wohnung passieren, wobei nicht zu übersehen ist, dass die Mutter wiederholt zum Alkohol Zuflucht nimmt, um so ihre Schmerzen zu lindern. Klemmer schlägt Erikas Mutter zu Boden, stößt sie brutal in ein Zimmer und schließt sie dort ein. Erika wird ebenfalls von ihm geschlagen, wodurch die im Brief fixierten sexuellen Praktiken teilweise in die Tat umgesetzt werden (JELINEK 2005:268-278). Wenn man die von Erika ausgedrückten Wünsche mit ihrer von Klemmer vollzogenen Realisierung vergleicht, stellt sich heraus, dass er zwar ihre sexuellen Bedürfnisse erfüllt, aber auch gewisse Modifikationen in ihrer Ausführung vornimmt. Erika wird nicht gefesselt, obwohl eine bestimmte Form des Festbindens stattfindet: In einem Moment erinnert ihr Körper an die Kugel, die - mit einem Embryo verglichen - auf das Verlassen des mütterlichen Körpers hinweist. Der Gewinn des eigenen Körpers wird von dem Vergleich Erikas mit einem aus dem Boden in die Höhe schießenden Baum und von den Schmerzen angedeutet, die schon nach dem ersten Besuch von Klemmer in ihrer Wohnung zu ahnen waren, nachdem sie ihn mit dem Inhalt des Briefes vertraut gemacht hatte (JELINEK 2005:253f.). Indem sie unter dem Einfluss von Klemmer bleibt, beginnt sie den Schmerz zu empfinden, den sie mit der Rasierklinge einübte. In diesen Schmerzen, zu denen auch Klemmers Brutalität beiträgt, spiegeln sich die Geburtswehen wider, deren Folge sowohl die Tränen der Tochter als einer sich selbst Gebärenden als auch die der Mutter als einer das Kind Gebärenden sind und die auf die Vollendung der Geburt von Erika hinweisen. Die Geburtsvollendung wird jedoch in dem Moment zunichte gemacht, in dem Erika vergewaltigt wird. Dadurch, dass Klemmer gegen die im Brief fixierten Dispositionen von Erika verstößt und so die Initiative übernimmt, wird Erika wieder auf die Position zurückgebracht, die ihr ihre Mutter als Hüterin des sich in der initiatorischen Freiheit ausdrückenden Patriarchats zugewiesen hat 
(SzCZEPANIAK 2005:152). Zwar sind die Elemente von Erikas sexuellem Szenarium im Handeln von Klemmer zu erkennen, aber er lässt die enge Verbindung aus, die eine wichtige Voraussetzung für die Lösung ihres Körpers vom Körper ihrer Mutter bildet, und vergewaltigt sie, wodurch er in ihren Körper und nicht sie in seinen Leib mittels ihrer in seinen After gesteckten Zunge dringt, wie es in ihrem Brief geschrieben stand (JELINEK 2005:229). Erikas Plan, ihren Körper aus der Mutter ,herauszuführen“, stützt sich auf die schon von dem dritten Kampf gegen die Mutter her bekannte Imitation der Rolle eines Mannes, deren Simulierung die als Penis angewendete Zunge von Erika betont. Zwischen der Zeit, in der Erika Klemmer ihren Brief präsentiert, und der Zeit, in der sie von ihm missbraucht wird, steht sie unter dem Einfluss eines Mannes, bei dem ihre Entwicklung als eines mit der eigenen Form versehenen Individuums immer realer wird. Die Umbrüche im Prozess der Befreiung von der Mutter sind im Kontext ihrer drei ,Konfrontationen“ mit Klemmers Penis sichtbar. Beim ersten Mal scheint das steife Glied von Klemmer für ihre Mutter vorgesehen zu sein, denn der Körper von Erika als ein Körper, der mit dem der Mutter zusammengewachsen bleibt, reagiert kaum auf Klemmers Erektion. Das zweite Mal dagegen kann Klemmers Glied den versteiften Zustand nicht erreichen, den aber Erika gewinnt, weil ihr Körper immer starrer wird und sich konturenmäßig immer mehr von der Mutter abhebt. Schließlich markiert das dritte ,Treffen' Erikas mit Klemmers Penis die gelungene sexuelle Penetration von Erika, die aber mit ihrer - bisher nur von ihrer Mutter vollzogenen - Vergegenständlichung endet und sie der Mutter wiederbringt: Am Ende des Romans verliert sie ihre Gabe des Tastsinns, was beweist, dass sich die schwachen Konturen ihrer sich allmählich materialisierenden Form wieder völlig aufgelöst haben (JELINEK 2005:285). Das Messer, das sie am Ende des Romans zu ihrem Treffen mit Klemmer mitbringt und mit dessen Stechen sie sich für den Akt der Vergewaltigung zu entschädigen beabsichtigt, richtet sie letztendlich gegen sich selbst und erkennt, dass sie wieder gegen jegliche, auch brutale Berührung gefeit ist. Sträubt sich Eva in Bergmans Text aus Angst vor dem Rütteln an der von Gott geschaffenen Harmonie der Existenzen, Selbstmord zu verüben, so ist Erika wegen der erneuten Verschmelzung mit der Mutter außerstande, sich das Leben zu nehmen. Erika vermag sich nicht zu töten, weil ihre Mutter wieder alle Entscheidungsfunktionen übernommen hat, was sich gerade in dem Moment bewahrheitet, in dem sie sich ihren Arm verletzt: Sie entdeckt, dass ihre knospende Fähigkeit zum Spüren wieder auf den Körper der Mutter zurückgesprungen ist. So verliert sie ihre Chance auf Unabhängigkeit, die sich - KARL JASPERS (1977:104) zufolge - 
in der Bereitschaft zum Selbstmord geltend macht und die Jessie, Protagonistin des Films Night, mother [Nacht, Mutter] (1986), verwirklicht, indem sie gerade von der Mutter in den Selbstmord getrieben zu werden scheint: Wenn die Mutter an die Sorge der Tochter appelliert und sie so am Leben zu halten versucht (MOORE 1986:1:24:00-1:29:00), erreicht sie das Gegenteil, weil die Tochter diesen Appell als Ansage der Belastung mit den Problemen der Mutter versteht.

Dadurch, dass Erika ihre sexuellen Erwartungen nicht mündlich, sondern brieflich übergibt, signalisiert sie, dass sie keine Form hat. Klemmer entnimmt die Worte dem Briefbogen als Geschriebenes und nicht als Gesagtes ihrem Körper, der so beschaffen wie das Wort ist: Bildet der Körper die Hülle für das Innere des Menschen, so gelten die Wörter als ,Muscheln' ihrer Bedeutungen. Dass Erika die Gefühle nicht mit der Form vertauschen, d.h. sie nicht völlig in den Musikbereich befördern will, wird klar, wenn Klemmer im Brief zwischen den Zeilen zu lesen hat, dass er ihr doch nicht weh tun sollte (JELINEK 2005:230). Indem sie sich nach dem Schmerz sehnt, ohne vom Schmerz zu Tode gequält werden zu wollen, und indem sie eine Vergewaltigung anstrebt, ohne vergewaltigt zu werden, gibt sie zu verstehen, dass sie die Umrisse der Form schon bekommt, wenn sie sich nur dem Schmerz nähert. Der Mangel an Kohärenz zwischen dem Gesagten bzw. Geschriebenen und dem Gewollten (CHOŁUJ 2008:25) bei Erika zeugt davon, dass sie die ,Schärfe ' der Form des Wortes - also die Ränder, die ihr Körper nicht besitzt -, und nicht die ,Schärfe ' von dessen Inhalt - also nicht das Brutale, das im Wort steckt - begehrt. Dass Klemmer als Formgeber auftritt, wird schon in dem Moment suggeriert, in dem er entscheiden darf, welches Kleid Erika anziehen soll, in das sich nicht mehr ihr Phantom, sondern sie sich selbst als eine Frau aus Fleisch und Blut einsetzt. Noch eindeutiger wird diese Funktion von Klemmer, als er Erika schlägt und ihre Form mit Fußtritten schnitzt (JELINEK 2005:275). Zwar gab es auch Schlägereien zwischen ihr und der Mutter, aber Klemmer scheint Erika eine Form zu verleihen, die sie vor der Mutter schützt. Konkaves und Konvexes der Form des Mannes werden nämlich derart in die Form der Frau gedrückt, dass sie sich mit der Form einer anderen Frau nicht verzahnen lässt, weil ,Ein'- und ,Ausschnitte der Körper von demselben Geschlecht auf der gleichen Höhe situiert sind. Erika arbeitet auch selbst an der Einsetzung ihres Inneren in eine Form: Wenn sie von einer Schürze mit ausgeschnittenen Löchern für die Geschlechtsteile spricht, serviert sie sie Klemmer fast auf dem Tablett, wodurch angedeutet wird, dass sie diese Organe für untauglich hält und abzugeben bereit ist. Eine ähnliche Funktion hat auch Erikas Forderung nach den von 
dem Mann zu erlassenden Verboten, die immer eine Grenze ziehen und einen Rahmen formen. Indem Klemmer aber seinen Penis in ihre Vagina einführt, richtet er Erikas Hoffnung auf die Form zugrunde und lässt sie so in ihrer Einsamkeit untergehen, deren Unerträglichkeit ein gelungener Schritt zur formbedingten Selbständigkeit hätte ausbalancieren können (KASZYŃSKI 2006:61). In diesem Augenblick verwandelt sich Klemmer vom Geber der Form in den Geber des Inhalts, den Erika schon besitzt und den er in Erika ,hineinspritzt', wodurch die Wände der sich schwach abzeichnenden Form wie ein Ballon durchstochen werden. Aus dieser Perspektive scheint Erikas Drang nach dem Urinieren in sexuell geprägten Situationen verständlicher: Indem sie sich des Urins in einem auf den Effekt des Blutentzugs berechneten Akt entledigt und sich so innerlich entleert, strafft sich ihr Körper, der in krampfhaft-pulsativen Bewegungen die Erfassung der Form zu provozieren versucht.

Charlotte hat bei der Geburt den Körper von Eva so weit von sich geworfen, dass sie von diesem Ereignis ausschließlich die Geburtsschmerzen im Gedächtnis behalten hat. Die Mutter von Erika dagegen hat den Körper der Tochter nur auf die andere Seite des Bauches gewälzt, so dass sie und ihr Kind ununterbrochen als zusammengewachsene Organismen funktionieren. Die Existenz der beiden Mütter hängt mit der Musik zusammen, die zugleich die Situationen der Frauen erhellt: Innerhalb des Musikbereichs als eines rein individuellen Sich-Erlebens-Spektrums gibt es nur Ein-Personen-Plätze, deshalb wird die Existenz der Tochter von Evas Mutter getilgt und von Erikas Mutter verschlungen. Wenn Charlotte von der Musikwelt abgestoßen und für einige Zeit in den mit ihrer Tochter geteilten Alltag eingepfercht wird, beginnt sie ihr Kind nach ihrem eigenen Identitätsmuster zu formen und in sich - in einer der Geburt entgegengesetzten Richtung - ,zurückzusaugen“. Die in ihre Mutter ,eingesaugte "Erika dagegen versucht aus der Musikwelt, in die sie von der Gier nach einer privilegierten Gesellschaftsposition und von einer durch die Tochter zu realisierenden Selbstverwirklichungsidee der Mutter eingesperrt wird, zu flüchten, um sich zu verselbständigen und sich als ein völlig autonomes Wesen zu Ende zu gebären. Die Annäherung Evas an ihre Mutter sowie die Scheidung Erikas von ihrer Mutter werden reich an Gewalt und halten nicht lange: Evas Mutter kehrt in die Musikwelt zurück, obwohl die Tochter ihr einen Gnadenerlass für ihr Rabenmuttertum erteilt hat; Erikas Mutter dagegen erlebt die Rückkehr der Tochter, die ihre dank einem Mann - Klemmer - mögliche Chance auf Souveränität verloren hat. Die Situation der Protagonistinnen ist besonders tragisch, als die Musik Evas Mutter von sich stößt und in die Arme der Tochter wirft, und als Erika, nach- 
dem sie von Klemmer verlassen worden ist, in die Welt der Musik zurückkehrt, wo sie ihre Mutter mit ihren Armen wieder umschlingt. Das gestörte Verhältnis zwischen Mutter und Tochter lässt sich auch am Verhältnis der Töchter zur Form ablesen: Während Erika aus der mütterlichen Enge herauszutreten versucht und nach einer ihr einen eigenen Platz in der Wirklichkeit sicherstellenden Form sucht, scheint sich die Form von Eva zu erübrigen, weil die Sehnsucht nach der immer weit weg von ihr weilenden Mutter die Beschaffenheit ihrer Person derart geändert hat, dass sie sich über die Grenzen der Wirklichkeit hinausstreckt und außerhalb der Realität existieren kann.

\section{Filme}

Bergman, INGMAR (1972): Viskningar och rop. [Schreie und Flüstern].

- (1978a): Höstsonaten. [Herbstsonate].

Clifford, GRAEME (1982): Frances.

Haneke, Michael (2001): La Pianiste. [Die Klavierspielerin].

MOORE, TOM (1986): Night, mother.

VisCONTI, LuCHINO (1969): The Damned.

\section{Literatur}

Andersen, Hans Christian (2003): Märchen. Aus dem Dänischen von Heinrich Denhard. Stuttgart.

ANTONIEWICZ-DURCZAK, DARIA (1992): Literackość scenariuszy Ingmara Bergmana. [Das Literarische der Drehbücher von Ingmar Bergman]. Poznań [Unveröffentliche Dissertation, entstanden an der Adam-Mickiewicz-Universität in Posen; Betreuerin: Prof. Dr. Maria Krysztofiak-Kaszyńska].

BERGMAN, INGMAR (1978): Höstsonaten. Lund.

- (1980): Herbstsonate. In: Bergman, IngmaR: Herbstsonate. Von Angesicht zu Angesicht. Aus dem Schwedischen von Hans-Joachim Maass. Berlin.

Bettelheim, Bruno (1980): Kinder brauchen Märchen. Aus dem Englischen von Liselotte Mickel und Brigitte Weitbrecht. München.

ChoŁuJ, BożEnA (1995): Matki i ich władza w literaturze niemieckiej. [Die Mütter und ihre Macht in der deutschen Literatur]. In: Teksty Drugie 3/4:141-157.

- (2008): Ciało w dramatach Jelinek (, Co sie zdarzyto ...”, „,Clara S.”, „Zajazd albo tak czynia wszyscy“). [Der Körper in den Dramen von Elfriede Jelinek (,,Was geschah ...", „Clara S. “, „Raststätte oder Sie machens alle“)]. In: SZCZEPANIAK, MONIKA (ed.): „Mówię i mówię“. Teatralne maski Elfriede Jelinek. Bydgoszcz, 23-32. 
Cornejo, Renata (2006): Das Dilemma des weiblichen Ich. Untersuchungen zur Prosa der 1980er Jahre von Elfriede Jelinek, Anna Mitgutsch und Elisabeth Reichert. Wien.

DRYNDA, JoAnNa / DZiKowska, KATARZYNA (eds.): Labyrinthe der Erinnerung. Beiträge zur österreichischen Literatur. Festschrift für Prof. Stefan H. Kaszyński. Poznań.

Gallas, Helga (2007): Suchfigur Ulrike Meinhof in Elfriede Jelineks „Ulrike Maria Stuart“. In: GUTJAHR, ORTRUD (ed.): Ulrike Maria Stuart. Tübingen, 97-105.

HAMmer, Klaus (2007): Elfriede Jelinek - die Kassandra der Literatur des 21. Jahrhunderts. In: WERBIŃSKA, DOROTA / WIDAWSKA, BARBARA (eds.): Wschód-Zachód. Dialog kultur. Studia nad literatura i językiem. Bd. 2. Słupsk, 35-39.

HoffMANn, ERnSt TheOdor AmAdeus (2005): Der Sandmann. Stuttgart.

JaBŁKOWSKa, JoAnNa (2006): Das nicht (mehr) glückliche Österreich, seine erste (Un)Dame Elfriede Jelinek und ihre gemeinsamen (Un)Toten. In: DRYNDA / DZIKOWSKA, 265-281.

JANZ, MARLIES (1995): Elfriede Jelinek. Stuttgart/Weimar.

- (1997): „Die Geschichte hat sich nach 45 entschlossen, noch einmal ganz von vorne zu beginnen... “. Elfriede Jelineks Destruktion des Mythos historischer ,Unschuld'. In: Bartens, Daniela / Pechmann, Paul (eds.): Elfriede Jelinek. Die internationale Rezeption. Graz/Wien, 225-238.

JASPERS, KARL (1977): Chiffren der Transzendenz. München.

JELINEK, ELFRIEDE (2005): Die Klavierspielerin. Reinbek bei Hamburg.

KASZYŃSKI, STEFAN H. (2006): W cieniu habsburskich krajobrazów. Trzynaście esejów o literaturze austriackiej. [Im Schatten der Habsburgischen Landschaften. Dreizehn Essays über die österreichische Literatur]. Poznań.

KOŁAKOWSKI, LESZEK (2005): O co nas pytaja wielcy filozofowie. [Wonach fragen uns die großen Philosophen]. Bd. 2. Kraków.

- (2006): Charyzmatyczny przywódca, charyzmatyczny nauczyciel. [Der charismatische Führer, der charismatische Lehrer]. In: Gazeta Wyborcza, 13./14.5.2006:13f.

KoŁODYŃSKI, ANDRZEJ (1978): Jesienna sonata. [Herbstsonate]. In: Film 48:22.

Liebrand, Claudia (2006): Traditionsbezüge: Canetti, Kafka und Elfriede Jelineks Roman „Die Klavierspielerin“. In: LÜTZELER, PAUl Michael / SCHINDLER, STEPHAN K. (eds): Gegenwartsliteratur. Ein germanistisches Jahrbuch. Tübingen, 23-49.

MAJKIEWICZ, ANNA (2008): Intertekstualność - implikacje dla teorii przektadu. Wczesna proza Elfriede Jelinek. [Intertextualität - Implikationen für die Übersetzungstheorie. Die frühe Prosa von Elfriede Jelinek]. Warszawa.

Mayer, Verena / Koberg, Roland (2006): Elfriede Jelinek. Ein Porträt. Hamburg.

MuNZAR, JIŘI (2005): Elfriede Jelineks Musikerinnen und die Bürger-KünstlerProblematik. In: KoPŘIVA, ROMAN / KovÁŘ, JAROSLAV (eds.): Kunst und Musik in der 
Wenn die Notenlinien zum Drahtverhau werden

Literatur. Ästhetische Wechselbeziehungen in der österreichischen Literatur der Gegenwart. Wien, 163-168.

OvID (2004): Metamorfozy. [Metamorphosen]. Wrocław/Warszawa.

PARANDOWSKI, JAN (1992): Mitologia. [Mythologie]. London.

PeŁKA, ARTUR (2006): Elfriede Jelinek. Femme fatale wspótczesnej literatury austriackiej. [Elfriede Jelinek. Die Femme fatale der gegenwärtigen österreichischen Literatur]. In: RUCHNIEWICZ, KRZYSZTOF/ ZYBURA, MAREK (eds.): Niemieckojęzyczni laureaci literackiej Nagrody Nobla. Wrocław, 241-260.

SARTRE, JEAN PAUL (1998): Egzystencjalizm jest humanizmem. [Der Existenzialismus ist Humanismus]. Aus dem Französischen von Janusz Krajewski. Warszawa.

Schmid-Bortenschlager, Sigrid / Schmid, Georg (2006): Diagnose. Jelinek und Bernhard. In: DRYNDA / DZIKOWSKA, 253-264.

SCHOPENHAUER, ARTHUR (2001): Welt und Mensch. Eine Auswahl aus dem Gesamtwerk von Arthur Hübscher. Stuttgart.

SEBALD, W. G. (1995): Unheimliche Heimat. Essays zur österreichischen Literatur. Frankfurt (M.).

Sugiera, Matgorzata (1997): Elfriede Jelinek: Demontaż powszednich mitów. [Elfriede Jelinek: Die Demontage der alltäglichen Mythen]. In: Dialog 3:176-189.

SzCZEPANIAK, MONIKA (2005): Kto się boi Elfriede Jelinek? [Wer hat Angst vor Elfriede Jelinek?]. In: Czas Kultury 5:143-160.

ZEYRINGER, KLAUS (2001): Österreichische Literatur seit 1945. Überblicke, Einschnitte, Wegmarken. Innsbruck.

ŻURAwieCKI, BARTosz (2007): Czy Bergman jest Polakiem? [Ist Bergman ein Pole?]. In: Film 6:50-52. 